\title{
Correlation of in situ oxazolidine formation with highly synergistic cytotoxicity and DNA crosslinking from combinations of doxorubicin and formaldehyde
}

Benjamin L. Barthel ${ }^{1}$, Erin L. Mooz ${ }^{1}$, Laura Elizabeth Wiener ${ }^{2}$, Gary G. Koch ${ }^{2}$, Tad H. Koch ${ }^{1, *}$

${ }^{1}$ Department of Chemistry and Biochemistry, University of Colorado Boulder, Boulder, Colorado 80309

${ }^{2}$ Department of Biostatistics, University of North Carolina at Chapel Hill, Chapel Hill, North Carolina, 27599

\section{Supporting Information}

Comet Assay Cartoon

Full statistical analysis of comet assay experiments

Detailed results of the restriction digest

Figure S1. Effect of drug treatment on NdeI digestion of SmaI-linearized pcDNA3.1(-)

Figure S2. Reaction progress versus time for NdeI enzymatic digests of SmaI-linearized pcDNA3.1(-)

Figure S3. Inhibition of NotI digestion of doxaz-treated linearized vector

Figure S4. Reaction progress versus time for NotI digests of SmaI-linearized pcDNA3.1(-) 


\section{Comet Assay Cartoon}
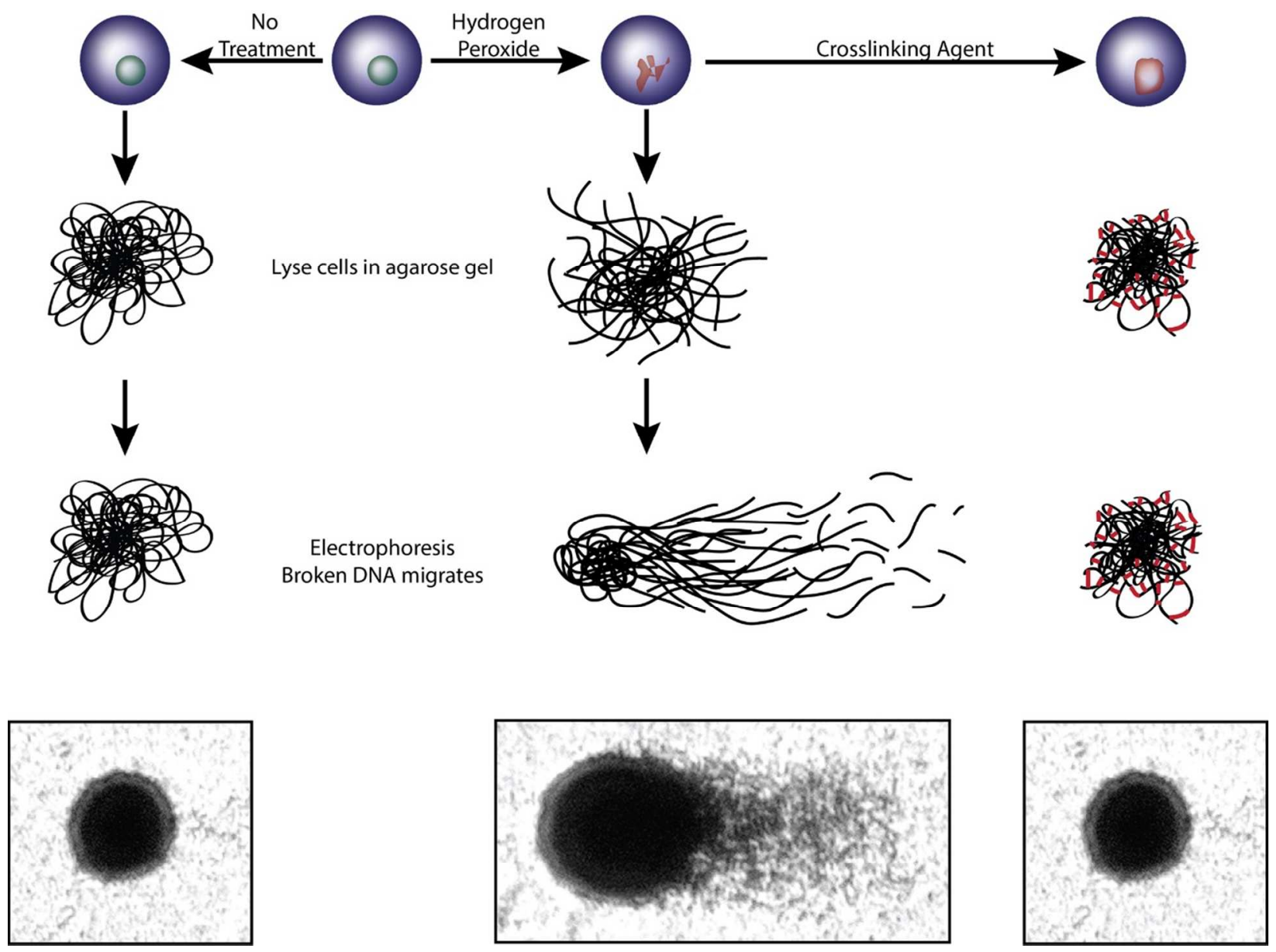

Full statistical analysis of comet assay experiments

\section{Study 1}

Table 1 shows the descriptive statistics for Study 1, organized by cell line and treatment group.

Table 1. Study 1 Descriptive Statistics

\begin{tabular}{cccccccc}
\hline & \multicolumn{3}{c}{ ADR } & & \multicolumn{3}{c}{ MP2 } \\
\cline { 2 - 4 } \cline { 6 - 8 } Treatment & $\mathrm{N}$ & Mean & SD & & $\mathrm{N}$ & Mean & SD \\
\hline Untreated & 119 & 5.7 & 6.96 & & 68 & 20.8 & 21.1 \\
$\begin{array}{c}\text { Dox }(100 \\
\mu \mathrm{M})\end{array}$ & 120 & 17.4 & 16 & & 78 & 37.1 & 18 \\
$\begin{array}{c}\text { Epi }(100 \\
\mu \mathrm{M})\end{array}$ & 120 & 22.7 & 9.25 & & 106 & 35.5 & 12 \\
$\begin{array}{c}\text { Doxaz } \\
(0.25\end{array}$ & 120 & 7.92 & 12.2 & & 96 & 21.1 & 11.8 \\
$\mu \mathrm{M})$ & & & & & & & \\
\hline
\end{tabular}




\begin{tabular}{ccccccc} 
Doxaz & 127 & 7.87 & 5.57 & 139 & 19.7 & 16.3 \\
\hline
\end{tabular}

Because all sample sizes are greater than 60, normal approximations are used for confidence intervals around the mean of each treatment group and are displayed in Figure 1.

Figure 1. Means and Confidence Intervals for Study 1

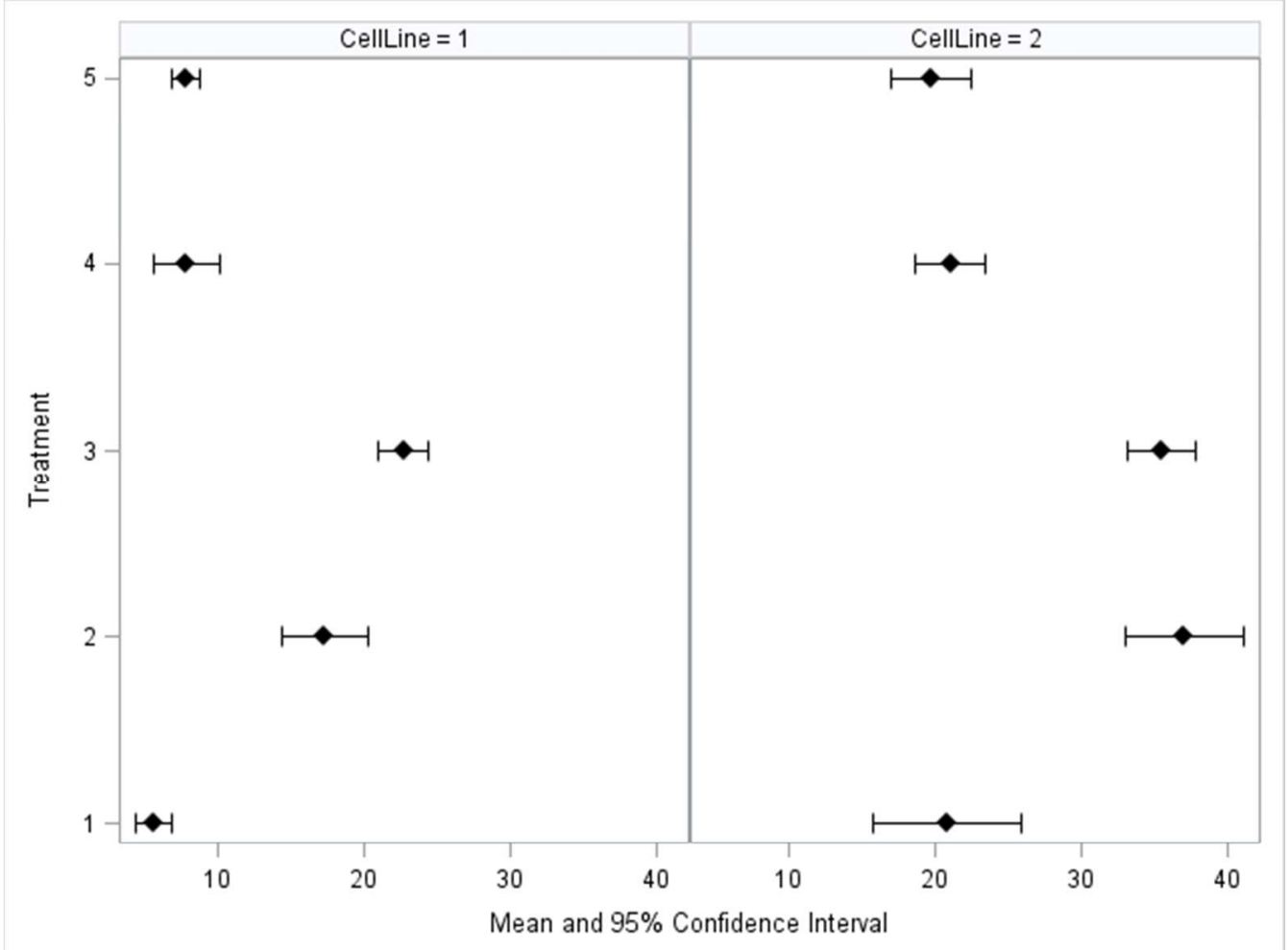

Additionally, Table 2 displays the p-values for the pairwise t-tests within each cell line and across cell lines.

Table 2. Pairwise T-Test P-values for Study 1

\begin{tabular}{|c|c|c|c|c|c|}
\hline & Untreated & $\begin{array}{c}\text { Dox } \\
(100 \mu \mathrm{M})\end{array}$ & $\begin{array}{c}\text { Epi } \\
(100 \mu \mathrm{M})\end{array}$ & $\begin{array}{c}\text { Doxaz } \\
(250 \mathrm{nM})\end{array}$ & $\begin{array}{c}\text { Doxaz } \\
(10 \mu \mathrm{M})\end{array}$ \\
\hline Untreated & $<0.001$ & $<0.001$ & $<0.001$ & 0.927 & 0.702 \\
\hline $\begin{array}{c}\text { Dox } \\
(100 \mu \mathrm{M})\end{array}$ & $<0.001$ & $<0.001$ & 0.518 & $<0.001$ & $<0.001$ \\
\hline $\begin{array}{c}\mathrm{Epi} \\
(100 \mu \mathrm{M})\end{array}$ & $<0.001$ & 0.002 & $<0.001$ & $<0.001$ & $<0.001$ \\
\hline $\begin{array}{c}\text { Doxaz } \\
(250 \mathrm{nM})\end{array}$ & 0.085 & $<0.001$ & $<0.001$ & $<0.001$ & 0.454 \\
\hline $\begin{array}{c}\text { Doxaz } \\
(10 \mu \mathrm{M})\end{array}$ & 0.008 & $<0.001$ & $<0.001$ & 0.967 & $<0.001$ \\
\hline
\end{tabular}

Note that the diagonal refers to p-values comparing the cell lines within the same treatment and that the pvalues for treatments comparisons for ADR are in the lower triangle and p-values for treatment comparisons for MiaPaCa-2 are in the upper triangle of Table 2. With adjustment for multiple 
comparisons with the Bonferroni-Holm method, statistical significance at the 0.05 level applies to all pairwise treatment comparisons with $\mathrm{p}<0.01$ within $\mathrm{ADR}$ separately or within MiaPaCa- 2 separately, as well as all comparisons between cell lines within the same treatment.

\section{Study 2}

Table 3 shows the descriptive statistics for Study 2 by treatment group.

Table 3. Study 2 Descriptive Statistics

\begin{tabular}{cccccccc}
\hline Treatment & N & Mean & SD & Treatment & N & Mean & SD \\
\hline 1 & 119 & 5.697 & 6.955 & 6 & 167 & 21.82 & 13.42 \\
2 & 103 & 47.07 & 22.86 & 7 & 131 & 78.07 & 16.51 \\
3 & 166 & 36.48 & 20.1 & 8 & 156 & 17.88 & 12.96 \\
4 & 155 & 66.36 & 20.65 & 9 & 139 & 31.51 & 18.61 \\
5 & 158 & 10.1 & 6.628 & & & & \\
\hline
\end{tabular}

Again, because the sample sizes are sufficiently large, confidence intervals for the mean of each treatment group are approximated with the normal distribution and displayed in Figure 2.

Figure 2. Means and Confidence Intervals for Study 2

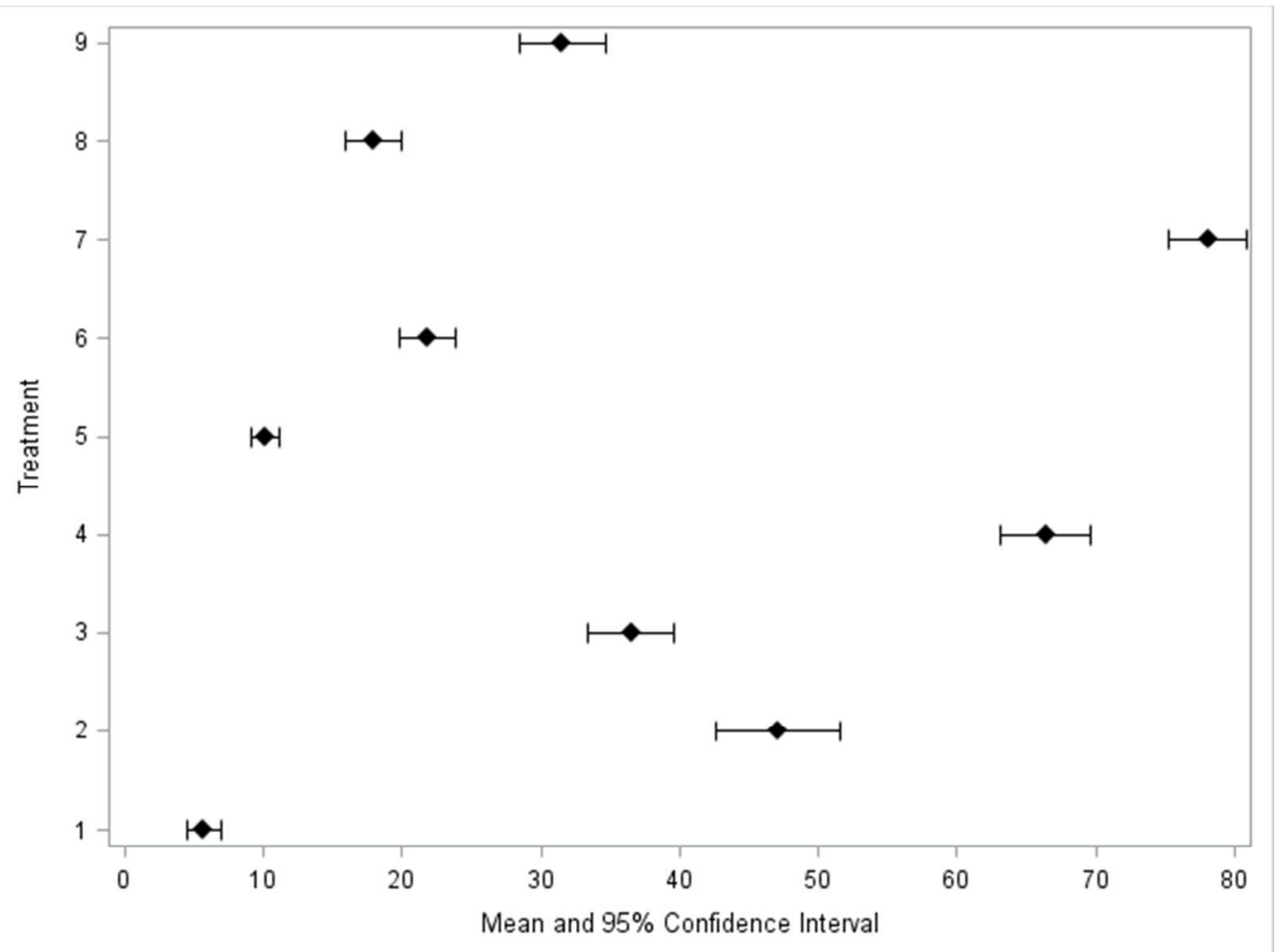

The p-values relating to the pairwise t-tests with the Satterthwaite approximation for the degrees of freedom were all less than 0.001 except for the comparison of Treatment 6 versus Treatment $8(\mathrm{p}=0.0076)$ and Treatment 3 versus Treatment $9(\mathrm{p}=0.0258)$. Statistical significance at the 0.05 level applies to all pairwise treatment comparisons via the Bonferroni-Holm method to adjust for multiple comparisons. 


\section{Study 3}

Table 4 shows the descriptive statistics for Study 3 by treatment group and the $95 \%$ confidence intervals for the mean, based on the normal approximation.

Table 4. Study 3 Descriptive Statistics

\begin{tabular}{ccccc}
\hline Treatment & $\mathrm{N}$ & Mean & SD & $95 \%$ CI \\
\hline 1 & 132 & 12.983 & 12.822 & $(10.776,15.191)$ \\
2 & 110 & 77.344 & 13.697 & $(74.756,79.932)$ \\
3 & 107 & 28.309 & 10.457 & $(26.305,30.313)$ \\
\hline
\end{tabular}

The p-values relating to the pairwise t-tests with the Satterthwaite approximation for the degrees of freedom were all less than 0.001 and thereby statistically significant at the 0.05 level via the BonferroniHolm method to adjust for multiple comparisons.

\section{Other analyses}

Supplemental analyses using GEE methods agreed with the results from the pairwise t-tests.

\section{Doxaz reaction with DNA at GC-rich sequences}

Having demonstrated that doxaz treatment results in crosslinking of the DNA in cells, we wanted to show that the lesion is specific for GC-rich sequences. Further, we demonstrate that these crosslinks have functional consequences which are distinct from treatment with dox. For these experiments, we assessed the ability of the drugs to effectively inhibit the action of two restriction endonucleases. Linearized pcDNA3.1(-) plasmid exposed to dox or doxaz was cut with either NotI, which cuts both strands at the GC-heavy sequence of 5' GC/GGCCGC-3', or NdeI, which cuts both strands at the AT-rich sequence 5'CA/TATG-3'. The site of hydrolysis is indicated by the forward slash. Each cleavage sequence occurs only once in the vector and enzymatic activity results in two separate fragments from the single fulllength vector sequence. We predicted that dox and doxaz would show similar effects on NdeI kinetics, but that doxaz would have more profound effects on NotI hydrolysis.

Maxiprep-purified pcDNA3.1(-) vector was fully linearized with SmaI, then reacted with dox or doxaz $(1.5,5$, or $8 \mu \mathrm{M})$ for $30 \mathrm{~min}$ in HPLC-grade water. The digest buffers and enzymes were then added and time samplings taken for up to $2 \mathrm{~h}$. The reactions were analyzed by agarose gel electrophoresis and compared to each other and reactions containing vehicle (1\% DMSO) in place of the drug. To 
control for the possibility that the formaldehyde carried by doxaz could be having an effect on its own, formaldehyde alone was also tried at the intermediate dose $(5 \mu \mathrm{M})$ and a high dose $(15 \mu \mathrm{M})$, and neither of those concentrations had any significant effect on the DNA cleavage rate (data not shown). When cut with NdeI, dox-reacted DNA displayed a greater stability than the control (Figure 4 and 5A). The inhibition of the digestion was dose-dependent between $1.5 \mu \mathrm{M}$ and $5 \mu \mathrm{M}$, beyond which there was no increased inhibitory activity. Interestingly, doxaz-reacted DNA was easier for NdeI to cut than doxreacted DNA (Figure 4 and 5B). The $1.5 \mu \mathrm{M}$ doxaz reaction was similar to vehicle and the $5 \mu \mathrm{M}$ doxaz reaction was only slightly slower. Only at $8 \mu \mathrm{M}$ doxaz was the reaction dramatically inhibited. We interpret these results as being indicative that a fraction of the doxaz reacts with the DNA at other sites, leaving the remainder to hydrolyze to dox and behave as dox. The SmaI-linearized pcDNA3.1(-) was at a concentration of $7.8 \mathrm{nM}$ in the drug reactions. An examination of the vector sequence shows that each vector contains 411 5'-GC-3' sequences, for a final concentration for this sequence of $3.2 \mu \mathrm{M}$. If nearly all of the doxaz reacted with these 5'-GC-3' sites, the remaining amount of unreacted doxaz left to hydrolyze to dox was approximately $1.8 \mu \mathrm{M}$ and $5.3 \mu \mathrm{M}$ from a doxaz reaction of $5 \mu \mathrm{M}$ or $8 \mu \mathrm{M}$, respectively. Therefore, if doxaz has no crosslinking effects on the NdeI cut sequence, $5 \mu \mathrm{M}$ doxaz would be predicted to show similar inhibitory effects as $1.5 \mu \mathrm{M}$ dox, while $8 \mu \mathrm{M}$ doxaz would perform like $5 \mu \mathrm{M}$ dox. When these curves were overlaid (Figure 5C), this prediction was confirmed; the reaction progress for $1.5 \mu \mathrm{M}$ dox was nearly identical to that seen for $5 \mu \mathrm{M}$ doxaz and very similar in the case of 5 $\mu \mathrm{M}$ dox and $8 \mu \mathrm{M}$ doxaz.

In the GC-rich recognition sequence of NotI, reaction of the DNA with dox resulted in a small, but possibly dose-dependent effect on the rate of the cleavage reaction (Figure 6 and 7A). In every case, however, the starting material was fully cut by 60 - $80 \mathrm{~min}$. Reaction of the DNA with doxaz, however, has quite a different effect (Figure 6 and 7B). Here, a measureable fraction of the DNA appeared to be completely resistant to hydrolysis $(0.12$ at $1.5 \mu \mathrm{M}$ doxaz and 0.3 for $5 \mu \mathrm{M}$ and $8 \mu \mathrm{M})$, suggesting that doxaz treatment results in a long-term blockage of the GC-rich cut sequence. When taken together with the comet data presented above, we interpret these results as indicative that doxaz very quickly crosslinks 
DNA specifically at 5'-GC-3' sequences in a way that is functionally distinctive from lesions resulting from DNA exposure to dox.

Figure S1. Effect of drug treatment on NdeI digestion of SmaI-linearized pcDNA3.1(-). The DNA was treated with various concentrations of either dox or doxaz for $30 \mathrm{~min}$, followed by enzymatic digestion for $2 \mathrm{~h}$. Timepoints from the digest were analyzed by agarose electrophoresis and ethidium bromide staining. The cropped gel images shown below are representative of duplicated reactions, with each reaction analyzed twice in different regions of the gel to control for variations in loading and gel illumination, as well as gelling conditions.

\begin{tabular}{|c|c|c|c|c|c|c|c|c|c|c|c|c|c|c|c|c|c|c|c|}
\hline & & & & & & & & & & ntrc & & & & & & & & & \\
\hline & & Reac & ction & time & $(\min )$ & & 5 & 10 & 203 & 30 & 45 & 60 & 90 & 120 & & & & & \\
\hline Full-I & $\begin{array}{l}\text { ngth } \\
\text { Lars }\end{array}$ & $\begin{array}{l}\text { pcDN } \\
\text { ge pro }\end{array}$ & $\begin{array}{l}\text { NA3.1 } \\
\text { oduct }\end{array}$ & $\begin{array}{r}(5.4 \mathrm{k} \\
(3.8 \mathrm{~h}\end{array}$ & & 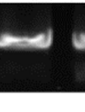 & $\rightarrow$ & $\rightarrow$ & 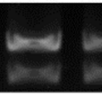 & $=4$ & 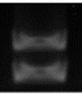 & 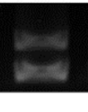 & $\therefore$ & $a$ & & & & & \\
\hline & & & & & Dox & & & & & & & & & & Doxaz & & & & \\
\hline & 0 & 5 & 10 & 20 & 30 & 45 & 60 & 90 & 120 & & 0 & 5 & 10 & 20 & 30 & 45 & 60 & 90 & 120 \\
\hline $1.5 \mu \mathrm{M}$ & 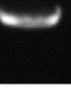 & os & $=$ & 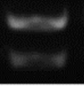 & $\because$ & $=$ & 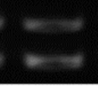 & $=$ & $t=$ & & $\Longleftrightarrow$ & 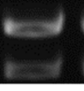 & $\Leftrightarrow$ & 5 & $\Leftrightarrow$ & $E$ & 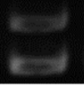 & 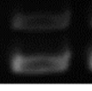 & 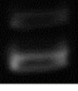 \\
\hline $5 \mu \mathrm{M}$ & $n$ & 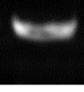 & 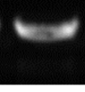 & $=$ & $=$ & $n$ & $10=$ & 10 & 15 & & $\omega$ & 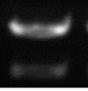 & 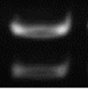 & 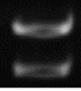 & 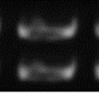 & 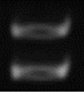 & 5 & $\square$ & $=$ \\
\hline $8 \mu \mathrm{M}$ & & $\Leftrightarrow$ & $\Leftrightarrow$ & 10 & $\Leftrightarrow$ & $\mathrm{ka}$ & $\Leftrightarrow$ & 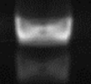 & 10 & & $=0$ & $\log$ & 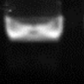 & 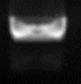 & $=0$ & 0 & $\Leftrightarrow$ & $n$ & $=0$ \\
\hline
\end{tabular}




\section{Figure S2. Reaction progress versus time for NdeI enzymatic digests of SmaI-linearized}

pcDNA3.1(-). The DNA was treated for 30 min with dox (A) or doxaz (B). Overlaying of the data (C), demonstrates that $1.5 \mu \mathrm{M}$ dox and $5 \mu \mathrm{M}$ doxaz reactions are similar, while $5 \mu \mathrm{M}$ dox and $8 \mu \mathrm{M}$ doxaz reactions are similar. The large fragment bands were analyzed by densitometry and the fraction of starting material remaining was calculated. Each point represents the mean of four measurements (duplicated reactions, each analyzed twice) and the error bars represent the standard deviation.
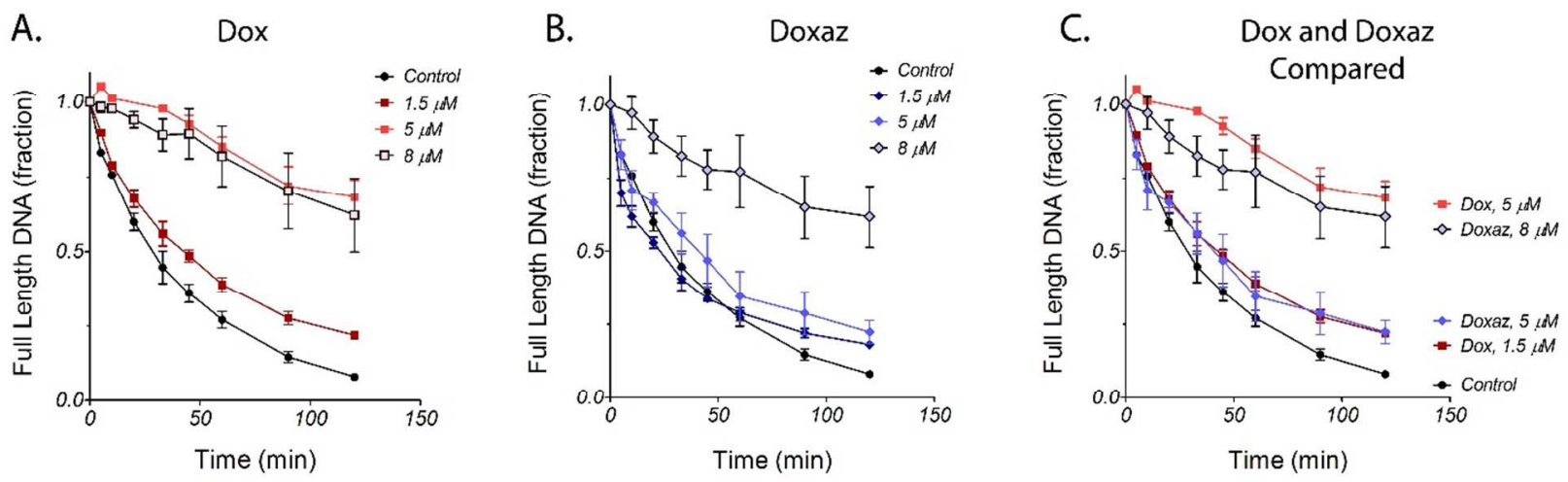
Figure S3. Inhibition of NotI digestion of doxaz-treated linearized vector. For the control, $1.5 \mu \mathrm{M}$, and $5 \mu \mathrm{M}$ conditions, the reaction was run for $80 \mathrm{~min}$. With $8 \mu \mathrm{M}$, the timecourse was extended to 120 min to demonstrate whether or not doxaz-treated DNA could be cut to completion.

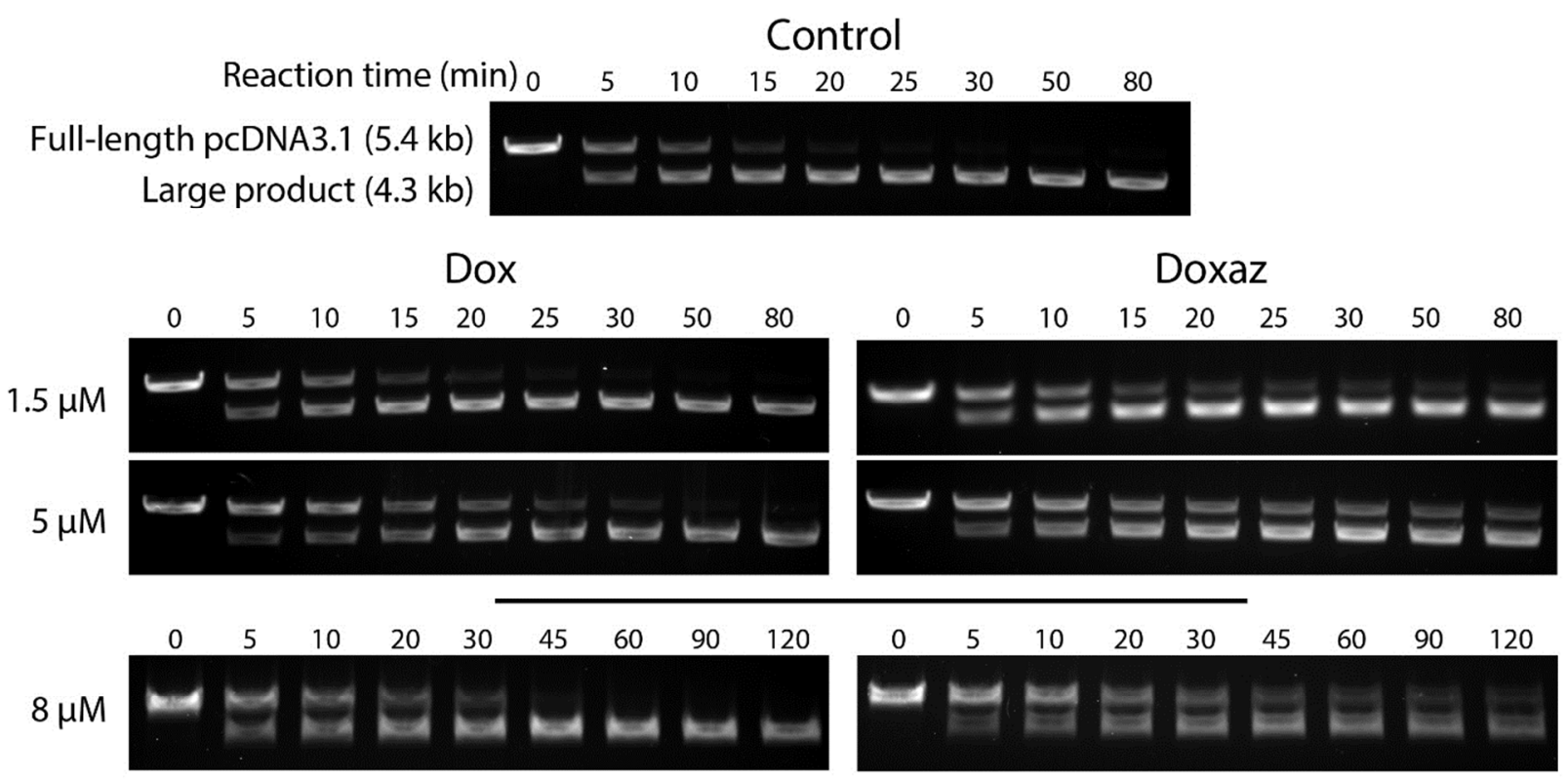

Figure S4. Reaction progress versus time for NotI digests of SmaI-linearized pcDNA3.1(-). The DNA was treated for 30 min with dox (A) or doxaz (B). Each point represents the mean of four measurements (duplicate reactions, each analyzed twice) and the error bars are the standard deviations.
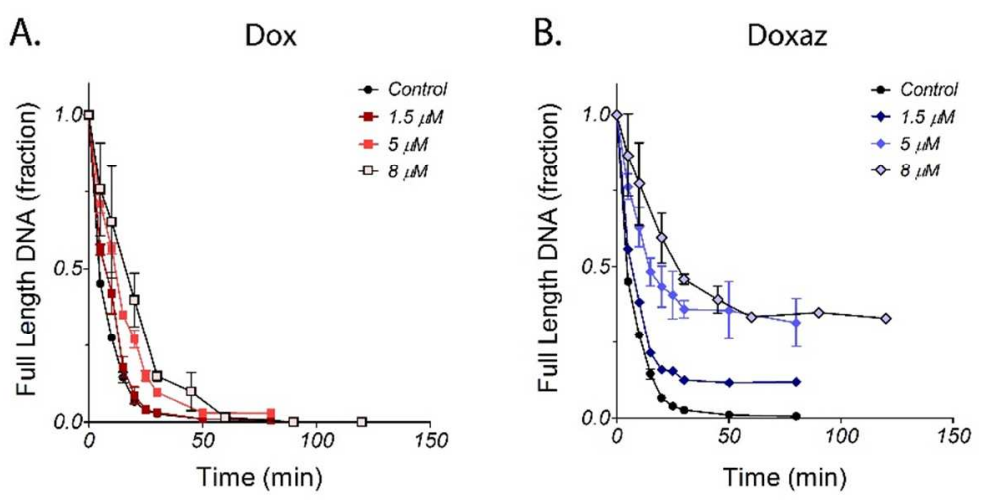
